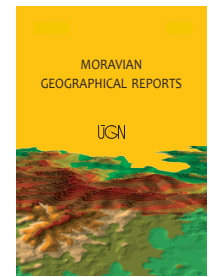

MORAVIAN GEOGRAPHICAL REPORTS

Institute of Geonics, The Czech Academy of Sciences

journal homepage: http://www.geonika.cz/mgr.html

doi: 10.2478/mgr-2019-0001

\title{
Is there congruence in the spatial patterns of regions derived from scalar and vector geographical information?
}

\author{
Martin ERLEBACH a , Marián HALÁS a , Jan DANIEL a , Pavel KLAPKA a *
}

\begin{abstract}
Selected traits of the spatial organisation of a geographical environment which stem from two types of human behaviour (locational and interactive) are examined in this paper. An attempt is made to find and account for similarities in the spatial patterns of scalar and vector geographical data. In doing so, the paper analyses a core-periphery dichotomy, based on socio-economic information, and travel-to-work patterns. The paper uses the concept of a region as an integrating and focusing framework for the study. Formal regions (peripheral areas) are defined through the application of principal components analysis and cluster analysis; functional regions are defined by a standard rule-based regionalisation algorithm. The territory of the Czech Republic is used as an area for testing the basic hypotheses. The results show that there is some form of interrelationship and complementarity between the spatial distribution of scalar data and vector data, i.e. between spatial structure and spatial interaction patterns, which together form the spatial organisation of a geographical environment.
\end{abstract}

Keywords: spatial organisation, human behaviour, spatial structure, core-periphery dichotomy, formal region, distance decay, spatial interaction, functional region, Czech Republic

Article history: Received 5 April 2017, Accepted 20 February 2019, Published 31 March 2019

\section{Introduction}

The spatial organisation of socio-economic phenomena is a long-lasting and recurring theme in geography and spatial science, and is represented and provoked by the seminal works of von Thünen (1826), Weber (1909), Christaller (1933), Lösch (1940), Perroux (1950), Isard (1956), etc. All of these foundational works were immensely inspiring for early quantitative geographers (see for instance the works of Berry and Garrison, 1958; Garrison, 1959a; Bunge, 1962; Curry, 1964; Haggett, 1965; and these are only a fraction of the total volume). These classic works have remained inspirational up to the present day (for a review, see Barnes, 2003), although they have encountered legitimate criticism, specifically based around the point that their concepts and conclusions are detached from very complex geographical realities.

Principally, the assumption of an isotropic space, the risk of privileging geometric representations of geographic space, and spatial separatism, have been the most asserted aspects of the criticism (see, for example, the early objections of Sack, 1972, 1973, 1974; or the Marxist-based discussions put forward by Soja, 1980). In this paper, we acknowledge the post-positivist approach of the so-called new quantitative geography (e.g. Barnes, 2004, 2010; Wyly, 2014), which is still based on the analysis of data, but which, among other factors, takes into account human behaviour and its influence on the "socially constructed" data used in quantitative analyses, stresses the importance of a geographical interpretation of results. Another piece of literature speaks of the critical quantitative geography, which acknowledges the need to fuse quantitative analysis with critical approaches based on challenging the spatialsocial structures induced by capitalist economy (e.g. Barnes, 2009; Kwan and Schwanen, 2009; Schwanen and Kwan, 2009). We stress particularly the interpretation of results in the current paper.

The theme of the spatial organisation of socio-economic phenomena is very extensive and thus offers the opportunity to choose from a great number of perspectives. In this paper, two distinct problems have been selected and pursued as two complementary parts of the spatial organisation of socio-economic phenomena, using a quantitative, datadriven approach. First, there is the issue of a core-periphery dichotomy in the spatial organisation of socio-economic phenomena; second, there is the issue of functional socioeconomic relationships in space, expressed for instance by

\footnotetext{
a Department of Geography, Faculty of Science, Palacký University Olomouc, Czech Republic (*corresponding author: P. Klapka, e-mail: pavel.klapka@upol.cz)
} 
one of the most frequent spatial interactions: travel-towork flows. This choice opens up a more general research question as the former (the core-periphery dichotomy) can be particularly dealt with through the analysis of scalar data and the use of the concept of a formal region, while the latter (travel-to-work patterns) is a typical example of vector data, which can be analysed within the concept of a functional region. Building upon Ullman (1980), scalar data define the site context, vector data define the situational context of human existence and activity.

Therefore the objective of the paper is to add modestly and partly to the question of whether there is a common influence acting on the spatial distribution of scalar and vector socio-economic data; that is, to seek evidence and explanation as to whether both distributions have corresponding and complementary patterns and if so, to what extent. In other words, the paper seeks to look for the congruence ${ }^{1}$ between the spatial distribution of locations and the spatial distribution of flows, in terms of their respective qualities and quantities. We can refer to the former as the spatial structure and to the latter as the spatial interaction pattern. The hypothesis to be reinforced is that, having the same agent, which is an individual, and having a common framework, such as an economic and a social system, there should be a certain dependence in the spatial arrangement of both types of information on human behaviour. Although the term "information" is used, with a broader meaning than the term "data" (Amedeo et al., 2009), it should be acknowledged here that the paper intentionally favours the quantitative approach to the issue raised, and that the analyses presented in the paper are based on statistical data.

The general objective of this paper needs further comment. The research question is very complex and cannot be solved in its entirety here, such that only a modest contribution to the complex field of the spatial organisation of society is put forward. What is the limiting framework of the current approach, which focuses the overall scope of the paper, then? Spatial structure and spatial interaction patterns are seen as manifestations of human behaviours, without further in-depth exploration of such behaviours. Apart from the roles of individuals and their aggregated behaviours, the concept of a region, as one of the oldest and most crucial geographical concepts, is employed in the present study in order to integrate various spatial manifestations of human behaviour and to focus the overall aim of the paper. Only a limited amount of geographic information is analysed. As the differences in the nature of scalar and vector information result in significant problems for any possible quantification of the research question, the paper explores only simple but feasible quantitative and graphical procedures in order to compare and assess the spatial distributions of scalar and vector geographical information.

Early attempts to analyse socio-economic geographical information on locations and flows date back to Garrison (1959b, 1960), although possible mutual interdependence in spatial terms was not discussed thoroughly. Berry (1968) put forward a general field theory of spatial behaviour, which attempts to synthesise scalar and vector information and define interdependency between them. This approach was criticised later by Greer-Wooten (1971), especially in terms of the procedures used. A literature review for the first period of this research is given by Griffith (1976). During the 1980s, this interdependence became a matter of increased attention (e.g. Bennett and Haining, 1985; Bennett et al., 1985). Only recently has similar research been carried out by Jones (2017), who used functional regions and notions of the urban hierarchy for his analysis.

There is also a relatively extensive literature combining spatial structure and spatial interaction in the field of spatial interaction modelling (see e.g. Curry, 1972; Cliff et al., 1974; Fotheringham and Weber, 1980; Fotheringham, 1981; and more recently, Tiefelsdorf, 2003; Griffith, 2007). With respect to the character of the information used in this paper, Griffith and Jones (1980) discussed the issue using the example of journey-to-work flows. Note, however, this group of works understands the term spatial structure differently than the current paper - or at least gives it a different quality. In these works, spatial structure is seen as "rigid" and model parameters reflect this given structure, in a similar manner to spatial autocorrelation indices. In contrast, we understand the spatial structure and spatial interaction patterns as a two-way flexible relationship, as an interdependence of two different types of information, both based on human spatial behaviour/ behaviour in space, which can lead to spatial congruence between spatial structure and spatial interaction patterns (see also footnote 1). What both conceptions have in common is that spatial structure reflects the distribution of scalar information. Nevertheless, even the works cited in this paragraph acknowledge the existence of an interdependence between underlying geographical structures and distancedecay, i.e. interaction, parameters.

In order to answer the questions posed, this paper starts with a discussion of the relevant theoretical background, including human behaviour as the crucial framework for further considerations, the concept of a region, the concept of a core-periphery dichotomy and geographical hierarchies, and the concept of spatial interactions and the role of distance. The next section uses the territory of the Czech Republic as a case study in order to validate the hypotheses. In this section, the necessary methodological information on the identification of formal regions (in this case peripheries) and functional regions in the Czech Republic are presented and the results are discussed. In this section we also attempt to assess in a simple quantitative and graphical way, a comparison of the results of the identified spatial distribution of scalar and vector information. The final section returns to the question of the congruence in the spatial patterns based on scalar and vector information and concludes with the associated findings.

\section{Theoretical background}

\subsection{Some notes on human behaviour in space}

All socio-economic geographical information for individuals can be seen as a reflection of human behaviour in a broader sense, including a wide spectrum of influences such as general psychological demands and cognitive perception,

\footnotetext{
1 The term congruence refers to obvious co-locations of place related information and place-to-place information of similar meaning in the sense that it expresses qualities such as centrality or peripherality, for instance. It must be noted however that this kind of spatial overlap or association can be induced by more or less latent interdependence between both types of information (scalar and vector) based on the human behaviour. Consequently there can be a certain kind of causal relation between spatial distribution of locations and spatial distribution of flows.
} 
physiological prerequisites, behavioural strategies, decisionmaking processes, the broader economic framework, etc. Moreover, every manifestation of human behaviour is rooted, affected and conditioned in a space (for overview see e.g. Frantál et al., 2012). As the issues of spatial behaviour and behaviour in space are extremely variable, this paper only briefly presents the necessary basics with regard to the two general types of data analysed.

Not only individual information on human behaviour but also its aggregation in space, is of utmost importance for geographical and spatial analysis. This aggregation can be seen from at least two perspectives: as a general aggregation of individual behaviours; and as a "corporate individual", that is some kind of institution (public or private), active and acting in various environments. Both of these perspectives are partly conditioned by spatial behaviour and partly influence spatial behaviour. In both cases, a number of tasks are accomplished and a number of demands are taken into account. This results in the great variety of human actions.

For the purposes of this paper, two types of behaviour, whether individual or aggregate, are important: (i) locational behaviour, (ii) and interaction behaviour. The first type includes choices of location made both by individuals and by "corporate individuals". The second type includes considerations of spatial relations between two or more intervening locations. Golledge and Stimpson (1997) offer two views of human behaviour in this respect: functionalist and behaviouralist. The former partly follows the laws of classic location and interaction theories, such as utility maximisation and effort minimisation. The latter view takes into account probabilistic and spatial choice theories (see e.g. Mattson and Weibull, 2002; Han and Timmermans, 2006), motivations and the gaining of information: it can be said to reflect the current socio-economic reality, which is framed for instance by the existence of such factors as globalisation, information and communication technologies, etc. What holds true in any case is that an individual seeks some benefits from a location and from an interaction, and not necessarily economic ones.

\subsection{Integrating concept of a region}

As stated above, in order to verify the hypotheses of the paper it is useful to apply the concept of a region, which has an integrating role in this respect. The crucial criterion for further classification of regions is the character of information, on which the region is based (e.g. Grigg, 1965, 1967; Johnston, 1970; Parysek, 1989; Gregory et al., 2009; Agnew, 2013). Scalar information defines formal regions and vector information defines functional region (see e.g. Fischer, 1987). Both types of information are responsible for distinct structural characteristics of regions and their relative autonomy. Thus, formal regions manifest their autonomy in their internal homogeneity and external separation with regard to the region-organising or regionbuilding information, and functional regions manifest in their internal coherence and external self-containment (see e.g. Smart, 1974; Fischer, 1987; Karlsson and Olsson, 2006; Farmer and Fotheringham, 2011; Klapka and Halás, 2016). As the result of these characteristics, the inner structure of formal regions is relatively simple (based on the hierarchical level, also the scale) and, in contrast, the inner structure of functional regions is significantly complex (see e.g. Klapka et al., 2013; Klapka and Halás, 2016). The spatial differentiation of a territory is based on different values of scalar region-building information, in the case of formal regions, and on characteristics such as intensity, orientation and length of vector region-organising information, in the case of functional regions.

As will be seen further in this paper, it is also suitable to distinguish between typological regions and individual regions (see e.g. Fischer, 1987). Typological regions consist of spatial units (region-building blocks) that need not necessarily be spatially contiguous; in contrast individual regions must be spatially contiguous in this respect. This classification has only a minor importance for the current paper, but it cannot be left out without this brief note.

\subsection{Core-periphery dichotomy and geographical hierarchies}

The division of space into developed (core) and less developed (peripheral) areas is a frequent phenomenon. As a matter of fact, it is not probable that areas with different environmental, historical, cultural and socio-economic conditions could develop in the same manner. This could only happen through an extremely strong levelling effort and intervention, which could negatively affect the usual competitive environment and jeopardise the external competitiveness of the territories (Halás, 2014). The analysis of the interactions between a core and a periphery is one of the basic research fields in human geography.

The core-periphery dichotomy can be analysed from four basic viewpoints (Leimgruber, 1994, pp. 8-11): geometric (i.e. spatial); social; economic; and ecological. From the temporal point of view, the dichotomy can be understood as a phenomenon that is:

1. relatively stable (including the attributes of location, population density, and transport infrastructure);

2. alterable in jumps (including the attributes of geopolitical position, participation in the world market); and

3. continuously alterable (including the econometric attributes).

The geographical view of the core-periphery dichotomy corresponds mostly with the geometrical approach and the first temporal characteristic, while the economic view builds upon the economic and social approach and on the third temporal characteristic.

The interdependence of the core-periphery dichotomy and the spatial distribution of flows and interactions was pointed out by Borgatti and Everett (1999). Using social network analysis, they tried to construct ideal images of core-periphery structures and to assess the extent to which these ideal images corresponded to real networks. They intuitively assumed that a core should be dense and cohesive and a periphery sparse and unconnected. Real structures can be approximated by various types of graphs, e.g. directed and undirected, valued and non-valued, etc. Concerning the orientation of flows and interactions, it should be noted that flows from peripheries to cores are prevalent. In contrast, Richardson (1977) was the first to use the term "polarisation reversal", pointing out that there are many alternative reverse flows and interactions, such as those oriented at new industrial locations induced by the presence of resources and labour force. Another example is the process of suburbanisation with prevailing outgoing flows from a centre.

There are two continua when exploring the coreperiphery dichotomy geographically: the one that occurs at a particular hierarchical level; and the one that is represented by a scale of hierarchical levels. As for the former, the transition from core areas to peripheral areas 
does not occur in jumps but is continuous. Based on this observation, Wallerstein (1979, pp. 95-118) introduced a transitional category, the 'semi-periphery'. Aware of the above-mentioned continuity, this paper uses the term "core-periphery dichotomy" as a symbolic simplification. As for the latter continuum, there are, in a generalised form, three hierarchical levels (Halás, 2014, p. 388):

1. global and supranational level (macro-regional level);

2. regional level (meso-regional level);

3. local level (micro-regional level).

The matter of scale is of crucial importance in geography (see e.g. Harvey, 1968), because different patterns and processes have different meanings and importance at different scales.

It is obvious from the preceding discussion that the phenomenon can be repeated at various hierarchical levels. Generally this is the case with fractals (Mandelbrot, 1967), as occurred in human geographic research in connection with Central Place Theory (Arlinghaus, 1985). Chen (2011, p. 619) points out the parallels in both theories and claims that the integration of the fractal theory into research in settlement and regional systems would contribute to the explanation of real dependencies in their spatial organisation. Halás (2014, p. 399) proposed a theoretical spatial model of the fractal arrangement of central and peripheral areas using the specific example of the Czech Republic (see Fig. 1). $\mathrm{He}$ also reminded us that in real space repeatability cannot be infinite, unlike theoretical fractal models, and it can only have a finite number of hierarchical levels.

\subsection{Spatial interactions and the friction of distance}

Spatial interactions can be seen as the aggregated manifestation of individual human behaviours in a space. They are induced by the heterogeneity of space and by various types of goals that an individual seeks to achieve and fulfil. In Human Geography, spatial interactions have no physical basis; they are rather influenced by psychological, economic and social factors. From the spatial perspective, the spatial interactions are conditioned by individuals' efforts to optimise their spatial "existence" (e.g. Zipf, 1947; Ullman, 1980; Fotheringham, 1986; Heldt Cassel et al., 2013; Halás et al., 2014a) and by the objective characteristics of space that can be articulated in the principles of

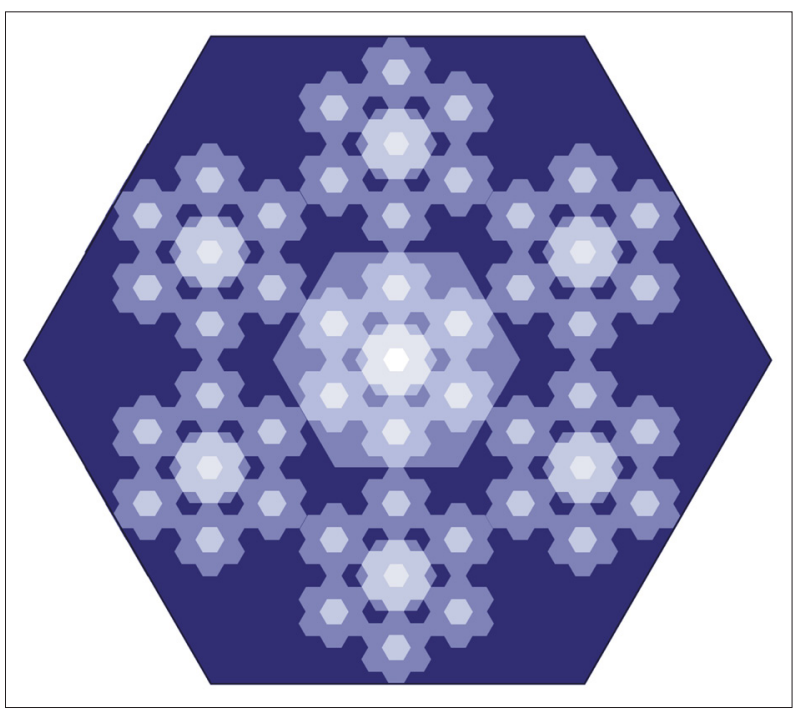

Fig. 1: Fractal arrangement of core (light) and peripheral (dark) areas. Source: Halás, 2014; adjusted complementarity, intervening opportunity, distance, etc. Distance, in particular, has frictional effects on the intensity of interaction as observed in Tobler's 'First Law' of Geography (Tobler, 1970), which can be paraphrased as "closer things are more closely related than distant things". This principle was later acknowledged by many researchers, including Alonso (1978), Sheppard (1978), Taylor (1983) and Stillwell (1991).

Spatial patterns of interactions and their characteristics, such as origins and destinations (i.e. direction) and intensity, have two important consequences. First they can be used for the definition of functional regions (see further comments, below), and second they are closely related to the concept of the core-periphery dichotomy. In the latter case, it is the socalled spatial polarity based on the dichotomy that affects the occurrence of horizontal spatial flows, and it can be assumed in a simplified way that peripheral areas have minimal or no interaction with core areas. In these areas, the boundaries of functional (particularly nodal) regions should be identified; nodal regions are special cases of functional regions - see Klapka et al., 2013; Klapka and Halás, 2016. This assumption can be seen to varying degrees at different hierarchical levels (see the preceding comments on fractals).

\section{Lessons from the Czech Republic}

In this section, the territory of the Czech Republic is used as a case study, where theoretical assumptions are tested. It consists of two methodological sub-sections, one dealing with the identification of typological formal regions (socio-economic peripheries), the other dealing with the delineation of functional meso-regions. The use of both types of socio-economic information, scalar and vector, is demonstrated. In the third sub-section, the results of both procedures are briefly commented on. The fourth subsection presents several simple quantitative approaches that can be used to assess congruence in the spatial distribution of scalar and vector geographical information, as well as a synthetic graphical outcome.

\subsection{Identification of peripheries}

The identification of peripheries is in fact a problem in the definition of typological formal regions. There are a number of ways to define formal regions, which use the procedures of multi-dimensional analysis (e.g. numerical taxonomy, graph theory). The traditional approach that can be used, even at the present, consists of two steps (see Berry, 1961, among others):

i. mathematical orthogonalisation of original variables and selection of explanatory components or factors; and

ii. clustering of spatial units in typological formal regions.

The first step uses principal components or factor analysis; the latter uses cluster analysis (for general overviews of particular approaches and methods, see e.g. Lattin et al., 2003; Gan et al., 2007, Everitt et al., 2011). The definition of formal regions was a particular interest for geographers in the 1960s and 1970s (e.g. Berry, 1961; Johnston, 1965, 1970, 1976; Lankford, 1969; Spence and Taylor, 1970, Cliff et al., 1975), but currently the issue is less frequently researched (e.g. Murray et al., 2014).

The identification of the socio-economic peripheries of the Czech Republic is based on the multidimensional analysis of 19 indices, calculated from the 2011 census data. All indices conform to those used for the identification of the peripheries in the territory of the Czech Republic in the past 
(Musil, 1988; Musil and Müller, 2008), in order to secure temporal comparability if needed. The indices can be divided into five groups:

1. indices of the age population structure (3 indices);

2. indices of the educational population structure (2);

3. economic indices (6);

4. indices on housing and household equipment (6); and

5. migration indices (2).

All indices are related to the so-called "general units" as defined by Musil and Müller (2008) and we refer to them further as the basic spatial units (BSUs). These units consist of both individual and amalgamated municipalities, which are the basic spatial units in the Czech Republic. The use of these basic spatial units enables one to compare achieved results with the existing works, and their lower number (in comparison to the number of municipalities of the Czech Republic) is more suitable for statistical operations and it also solves the problem of outliers.

For each basic spatial unit the following information/ variables have been collected:

1. Proportion of the population between 0 and 24 years of age in the total population;

2. Proportion of the population older than 60 years in the total population;

3. Number of widows per 100 women older than 60 years;

4. Proportion of the population older than 15 years without secondary school-leaving certificate in the total population older than 15 years;

5. Population with university education per 100 persons older than 25 years;

6. Number of job opportunities per 100 economically active employed persons;

7. Proportion of unemployed persons per the total number of economically active persons;

8. Proportion of job opportunities in agriculture, forestry and fishery in the total number of occupied job positions;

9. Proportion of job opportunities in industry and building in the total number of occupied job positions;

10. Proportion of employers and persons with business activities in the total number of economically active persons;

11. Proportion of economically active persons in tertiary sector in the total number of economically active persons;

12. Proportion of permanently inhabited dwellings in houses built between 1980 and 2011 in the total number of permanently inhabited dwellings;

13. Proportion of uninhabited dwellings in the total number of dwellings;

14. Number of dwellings in family houses inhabited temporarily or in recreational houses per 100 permanently inhabited dwellings in family houses;

15. Proportion of permanently inhabited dwellings with gas fixture in the total number of permanently inhabited dwellings;

16. Proportion of permanently inhabited dwellings with sewer connection in the total number of permanently inhabited dwellings;

17. Proportion of households with personal computer and internet connection in the total number of households;
18. Proportion of intrastate immigrants in the total population; and

19. Proportion of intrastate emigrants in the total population.

Standard procedures were used in the analysis: principal component and factor analysis and then cluster analysis. The combination of two approaches is referred to as Factor-Cluster segmentation (Dolnicar and Grün, 2009; Kibicho, 2010). Though the procedure is criticised, particularly in the context of tourism studies and the reduction in the number of variables (Dolnicar and Grün, 2011), it is still used to define regions based on socio-economic characteristics (e.g. del Campo et al., 2008; Palevičienè and Dumčiuvienè, 2015) and it offers two advantages. The first one lies in the reduction in the number of variables, despite what was noted earlier, which facilitates further operations. The second and more important advantage lies in the elimination of redundant correlated variables. The entire procedure is described in the following.

A standardised matrix of the values for 19 indices is processed by Principal Components Analysis (PCA) and four principal components (commonly referred to as factors) are extracted according to the Kaiser criterion (Kaiser, 1960). Their eigenvalues exceed 1 and their cumulative proportion of variance accounts for $66 \%$, which can be considered as sufficient explanation for the variability of the original indices. In the next step the transformation (rotation) of factors is carried out by the Varimax method in order to secure a better interpretation of results. The Varimax method is an orthogonal rotation, which produces factors that load highly on a limited number of the original variables, and load to a lesser extent on the rest of the original variables. It is a method that simplifies the factors. The simplicity function is given by the sum of variances of squared factor loadings in individual columns (Überla, 1971). Selected factors (F1-F4) can be characterised by the analysis of the factor loadings on individual original variables (U1-U19) - see Table 1.

Factor 1 is characterised by the highest weights of indices of employment, according to economic activity and branch, and by the educational population structure. Factor 2 strongly correlates with indices regarding the number of uninhabited dwellings. Factor 3 can be interpreted as the factor of employment and unemployment. Factor 4 strongly correlates with the age population structure.

The next step in the analysis is the calculation of factor scores of the selected factors (F1-F4) for all basic spatial units. There is a number of ways how to calculate factor scores that can be divided into two large groups: non-refined and refined (see e.g. Thompson, 2004; DiStefano et al., 2009; Uluman and Dogan, 2012). In this paper, the STATISTICA software was used for the analysis and it applies the refined regression method for the calculation of factor scores (Harman, 1976, p. 368). Refined methods aim to maximise validity by producing factor scores that are highly correlated with a given factor and to obtain unbiased estimates of the true factor scores.

Factor scores enter the next step of the multidimensional analysis instead of the values of the original indices. Cluster analysis is a method based on the comparison of the similarity of objects (BSUs) using taxonomic distance. We have used the agglomerative hierarchical procedure, where the results depend on the choice of linkage method and distance measure. We have tested the relevant combinations of centroid and Ward's linkage method and Euclidian and block taxonomic distance, which provided us with a set of four results. This choice was made according to the results 


\begin{tabular}{crrrr}
\hline \multirow{2}{*}{ Index } & \multicolumn{4}{c}{ Rotated factor loadings } \\
\cline { 2 - 5 } & \multicolumn{1}{c}{ F1 } & \multicolumn{1}{c}{ F2 } & \multicolumn{1}{c}{ F3 } & \multicolumn{1}{c}{ F4 } \\
\hline U1 & -0.107 & -0.138 & 0.047 & 0.853 \\
U2 & -0.124 & 0.251 & 0.015 & -0.854 \\
U3 & -0.284 & 0.131 & 0.226 & 0.317 \\
U4 & 0.749 & -0.232 & -0.417 & 0.084 \\
U5 & -0.739 & 0.239 & 0.493 & -0.027 \\
U6 & 0.121 & -0.013 & -0.968 & -0.010 \\
U7 & -0.121 & 0.013 & 0.968 & 0.010 \\
U8 & -0.287 & 0.672 & 0.147 & 0.081 \\
U9 & -0.792 & -0.203 & -0.074 & -0.051 \\
U10 & 0.688 & 0.372 & -0.056 & -0.016 \\
U11 & 0.878 & -0.233 & -0.128 & -0.009 \\
U12 & 0.387 & 0.016 & -0.396 & 0.546 \\
U13 & 0.043 & 0.866 & 0.039 & -0.272 \\
U14 & -0.010 & 0.806 & 0.056 & -0.253 \\
U15 & 0.118 & -0.693 & 0.015 & 0.009 \\
U16 & 0.210 & -0.571 & -0.033 & -0.003 \\
U17 & 0.402 & -0.414 & -0.536 & 0.314 \\
U18 & 0.348 & 0.125 & -0.104 & 0.187 \\
U19 & 0.026 & 0.074 & 0.227 & 0.047 \\
\hline
\end{tabular}

Tab. 1:. The rotated matrix of factor loadings

Source: Czech Statistical Office-2011 census, calculated by authors

Note: Highlighted values of factor loadings represent the strongest correlations with a relevant index

of some preceding geographical studies (e.g. Lankford, 1969; Byfuglien and Nordgård, 1973; Fischer, 1980; Margules et al., 1985) and according to the suggestions made for instance by Gordon (1987), Ferreira and Hitchcock (2009), Rogerson (2010), and Everitt et al. (2011). Ward's method identifies clusters, which are approximately similar in their sizes. The result of the cluster analysis is a grouping of spatial units into regional types.

The question is which result should be selected and how many clusters should be optimally used. In the paper the results reached by the application of block distance and Ward's linkage method are presented because they were favoured by the values of Silhouette coefficient (as calculated by the STATISTICA software), which is used to identify an optimal solution out of four possibilities and the optimal number of clusters (see Rousseeuw, 1987). Ten clusters, i.e. typological formal regions, were the best choice. Four clusters show the least favourable values (e.g. the highest unemployment rate, percentage of uninhabited dwellings, the lowest number of employed persons, percentage of the population without a tertiary education, etc.) of the analysed indices and these clusters are considered to identify socioeconomic peripheries. Two of these clusters are characterised by Factor 2 most importantly: they show the highest average values of score for Factor 2 (uninhabited dwellings). The remaining two clusters correspond most to the values of Factor 3 (employment and unemployment).

\subsection{Delineation of functional meso-regions}

The delineation of functional regions also has a long-lasting tradition in geography (see the overview in Casado-Díaz and Coombes, 2011, as well as Klapka and Halás, 2016). Apart from traditional graph theoretical approaches (e.g. Nystuen and Dacey, 1961; Holmes and Haggett, 1977) and more sophisticated graph theoretical and numerical approaches (e.g. Brown and Holmes, 1971; Masser and Brown, 1975; Kalsson and Olson, 2006; Farmer and Fotheringham, 2011; Kropp and Schwengler, 2014), probably the most successful approach is the family of rule-based algorithms devised at the Centre of Urban and Regional Development Studies (CURDS) in Newcastle (see e.g. Coombes et al., 1986; Casado-Díaz, 2000; Papps and Newell, 2002; Coombes and Bond, 2008, and others), although they have been questioned by some scholars (e.g. Cörvers et al., 2009; Farmer and Fotheringham, 2011; Watts, 2013). Only relatively recently, evolutionary algorithms have been used to define functional regions (e.g. Martínez-Bernabeu et al., 2012).

The definition of the functional meso-regions of the Czech Republic is based on the use of daily travel-to-work data. These data represent the most frequent regular and periodical daily movement of the population. Functional meso-regions can be identified by two approaches. Either basic spatial units (the smallest available with regard to the data used) are amalgamated, or some existing units at the micro- level are amalgamated into meso-regions. In this paper the latter approach is used. It has already been applied to the 2001 census data in the territory of the Czech Republic (for the results and discussion of several methods: see Erlebach et al., 2016). Functional microregions (in fact local labour market areas) defined by Klapka et al. (2016) are used as building blocks for further analysis in this paper.

Functional meso-regions are defined by the use of the third variant of the CURDS method (Coombes and Bond, 2008; Coombes, 2010), based on 2011 census data. This variant was slightly adjusted according to Halás et al. (2015), who used different self-containment measure and different constraint function. The procedure considers each basic spatial unit as a proto-regional core from the beginning and a crucial role is assigned to the operation with the so-called constraint function, which controls the trade-off between the size (number of employed persons in this case) and the self-containment of resulting functional regions. The values of four parameters (upper and lower limit of size, upper and lower limit of selfcontainment) are estimated using the approach proposed by Halás et al. (2015). First very low values for the parameters (size and self-containment) were set and larger number of primary regions was defined. These regions were put on the graph, where the $\mathrm{x}$ and $\mathrm{y}$ axes stand for the values of selfcontainment and size. Second a distinct gap is identified in the field of points and new parameters are estimated (this step can be repeated). These parameters provided us with the set of final regions (see also Halás et al., 2018).

The amalgamation of basic spatial units resides in the application of the Smart's interaction measure (Smart, 1974), which is given by:

$$
T_{i j}^{2} /\left(\sum_{k} T_{i k} \times \sum_{k} T_{k j}\right)+T_{i i}^{2} /\left(\sum_{k} T_{j k} \times \sum_{k} T_{k i}\right)
$$

where $T_{i j}$ is the flow from spatial unit $i$ into spatial unit $j, T_{j i}$ is the flow from spatial unit $j$ to spatial unit $i, \sum_{k} T_{i k}$ denotes all out-going flows from $i, \sum_{k} T_{k j}$ denotes all in-going flows to j, $\sum_{k} T_{j k}$ denotes all out-going flows from $j$, and $\sum_{k} T_{k i}$ denotes all in-going flows to $i$. After each amalgamation the interaction matrix is updated. This method enables one to set and adjust input parameters quite freely in order to optimise the resulting regional system. 


\section{Results and discussion}

The socio-economic peripheries of the Czech Republic based on the scalar data are shown in Figure 2. The spatial pattern is conditioned by the distribution of settlement centres, including the prominent macro-regional role of Prague and the distinct influence of meso-regional centres (see Fig. 2). According to the relative location of peripheries with respect to the state boundary, there are inner peripheries and outer peripheries conditioned by the existence of physiographic barriers to a considerable extent (e.g. the micro region of Jeseník - Figs. 2 and 3) Figure 2 also shows the spatial distribution of two types of peripheries: the first is characterised by the indices of employment and unemployment (Factor 3); whilst the second is characterised by indices concerning housing development, dwelling equipment and the number of uninhabited dwellings (Factor 2).
In the overall spatial arrangement of peripheries, the pattern presented is very similar to previously-identified peripheries (Musil and Müller, 2008; Bernard and Śimon, 2017). The latter work is also inspired by Musil and Müller (2008), and for the identification of peripheral basic spatial units they used a combination of factor analysis and simple clustering methods to group basic spatial units based on favourable/unfavourable values of indices according to Musil and Müler (2008).

The objective of Bernard and Šmon (2017), however, was not to identify one particular group of peripheral units, but types of peripheries, which are affected by various socio-economic factors. An important finding arising from the comparison of our project and other works is that between 2001 and 2011 the spatial pattern of the main peripheral areas did not change. It can be concluded that despite significant economic growth of the Czech Republic

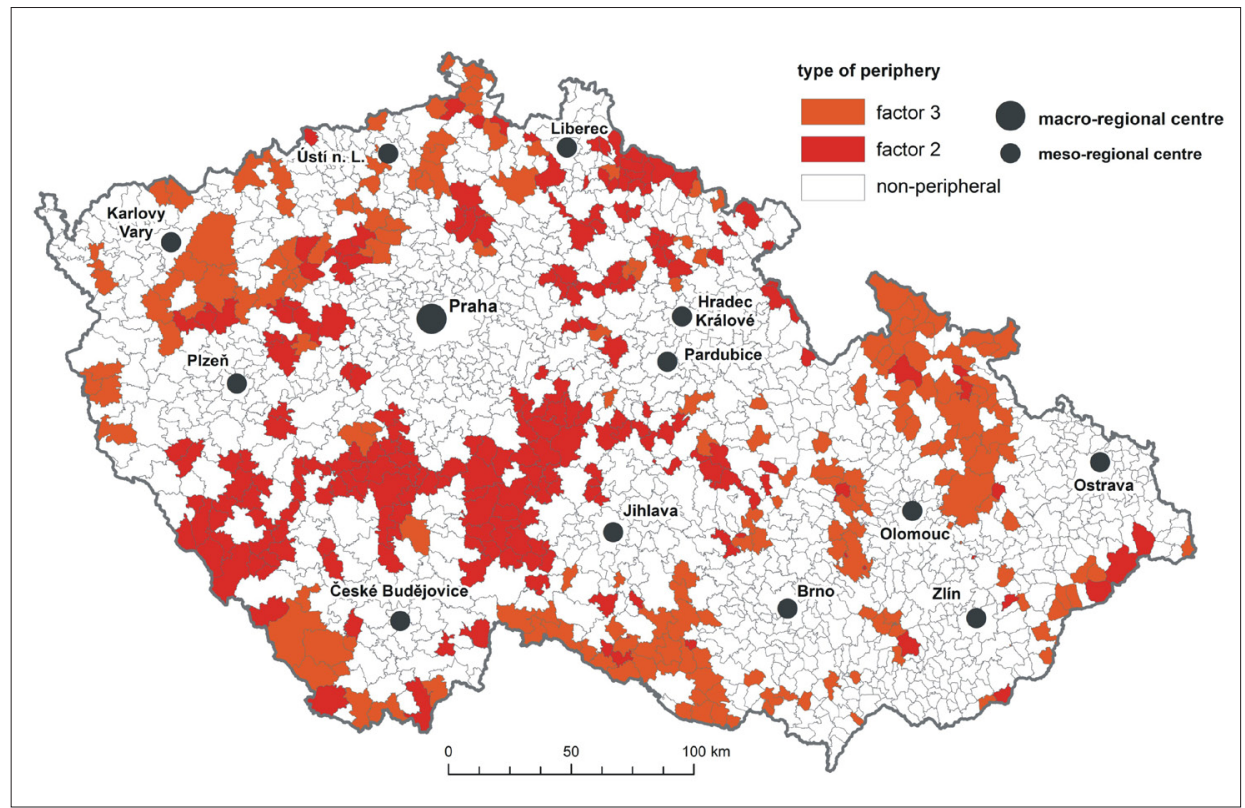

Fig. 2: Socio-economic peripheries of the Czech Republic (scalar data)

Source: Czech Statistical Office (2011 census), ÚRS Praha, a.s. (general units (BSUs)), authors' calculations

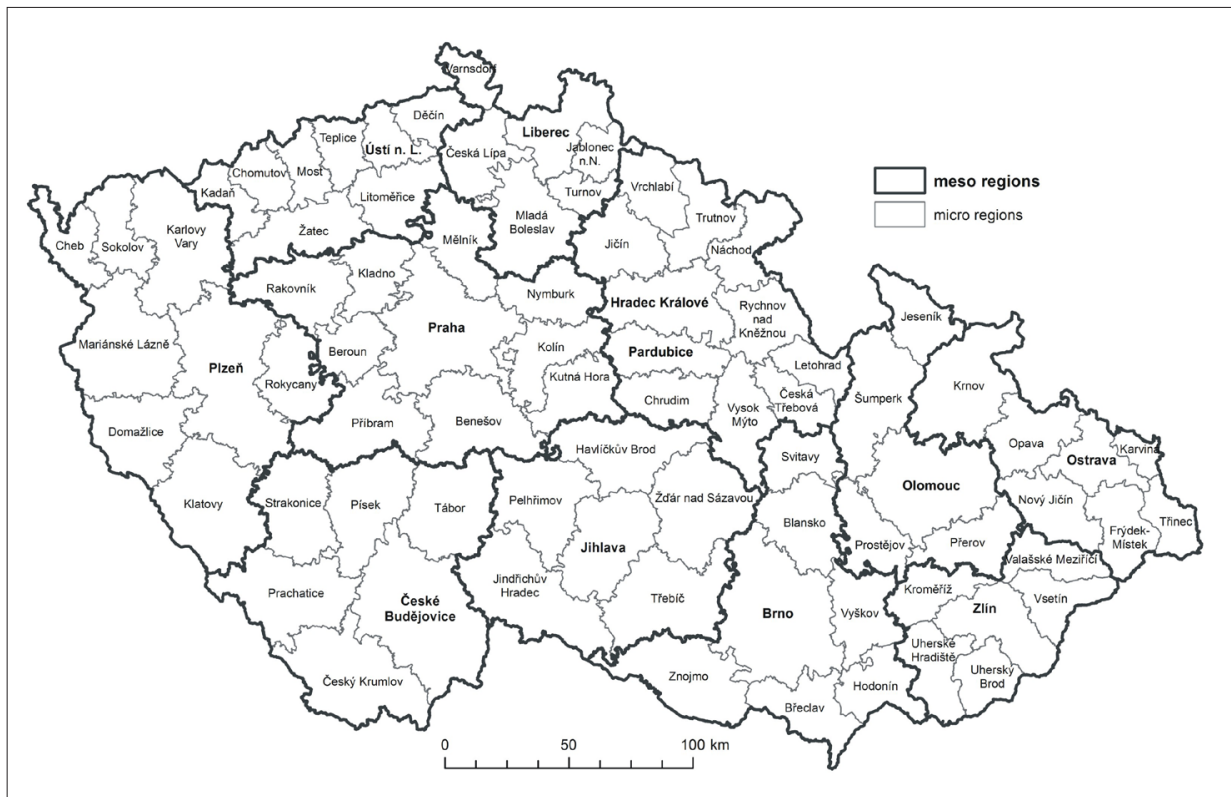

Fig. 3: Functional meso-regions of the Czech Republic (vector data)

Source: Czech Statistical Office - 2011 census, Klapka et al. (2016), own design 
in that period (Czech Statistical Office, 2016), the spatial pattern of socially and economically underdeveloped areas remained stable.

Functional meso-regions of the Czech Republic based on the analysis of vector data (daily travel-to-work flows) are shown in Figure 3. Eleven meso-regions are formed around the present administrative regional centres with three exceptions (the Czech Republic has 14 administrative regions). The first exception is the capital city of Prague, which is a stand-alone administrative region, a natural centre of central Bohemia at a meso-regional level and of the whole country at a macro-regional level. The second exception is a meso-region in eastern Bohemia, which has the form of a two-membered centre (the cities of Hradec Králové and Pardubice, which are both administrative regional centres). These two cities are located very close to each other and are related by strong mutual interactions. The third exception is the meso- region in western Bohemia with its regional centre in Plzen. This also includes the area around the city of Karlovy Vary. This centre is not able to organise its own meso-region. Detailed analysis of the 2001 commuting data has shown that according to the method used, the Czech Republic has between 8 and 12 mesoregions (Erlebach et al., 2016). Unlike the current work, the 2011 data clearly identify the functional meso-region formed around the city of Jihlava in a problematic area along the historical Bohemian-Moravian border. A similar spatial distribution of meso-regions can be found in the work of Halás et al. (2014b), who defined these regions using the distance decay function.

The congruence in the location of "non-peripheral areas" and "areas with high concentration of daily movements of the population" and in the location of "peripheral areas" and "areas with low concentration of daily movements of the population" is not easy to quantify in a direct sense, even though it can be graphically inspected, as in Figure 4.
The problem lies in the different character of both types of analysed geographical information and also in the way they are processed and expressed. If a correlation were to be calculated, the intensity (levels) of peripherality would have to be used, but this project identifies core and peripheral areas within the concept of formal region, which is a different objective. The use of some measure of correspondence would require relativised scalar and vector information, which would eliminate the effects of different sizes of basic spatial units. Scalar information is relativised with regard to one basic spatial unit and vector information with regard to a pair of basic spatial units, however. This prevents us from carrying out correct comparison. Therefore it is necessary to use absolute values for flows (vector data), though it is not a standard approach, nevertheless it gives us the exact analogy to graphical comparison in Figure 4.

In order to quantify the level of correspondence between locations of areas in question ${ }^{2}$ (as represented in Fig. 4), it is necessary to compare the number of non-peripheral BSUs to the same number of BSUs with the highest intensity of the commuting flows. This comparison shows us that the correspondence between two defined sets of BSUs (they have the same number of instances) reaches $84.5 \%$. If the level of correspondence were not expressed by the number of BSUs but according to the population, it would reach $96.5 \%$ : non-peripheral BSUs comprise a population 9,610,045 and BSUs with the highest intensity of flows have a population $9,944,759$.

Another way to compare the spatial distribution of vector and scalar information is to use results reached by the analysis of either vector or scalar data on one hand, and the results reached by the combination of both types of information on the other. In our case, from the set of non-peripheral BSUs based on scalar information (see Fig. 4) those non-peripheral BSUs, which did not manifest significant cross-border interaction (bi-directional vector of 100 and more persons),

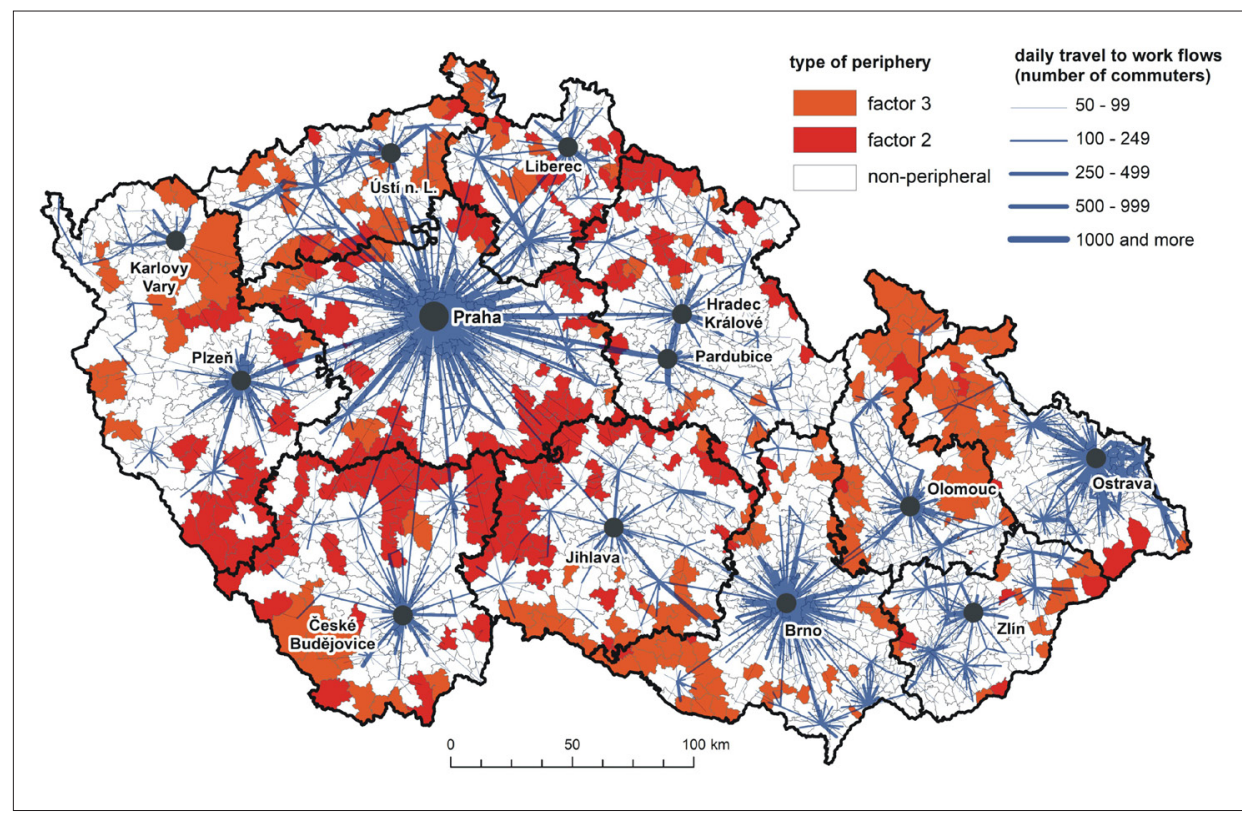

Fig. 4: Spatial arrangement of peripheries, boundaries of functional meso-regions and spatial pattern of interactions Source: Czech Statistical Office (2011 Census), ÚRS Praha, a.s. (general units (BSUs)), own calculations and design

\footnotetext{
2 There is a question whether canonical correlation analysis could be used for the purpose. In general this kind of analysis serves similar, analogous purpose well. But there is still practical or technical issue how to tackle vector information, which has an origin and a destination (see also the attempt of Berry [1968] and the notes of Greer-Wooten [1971]). Therefore we leave the possibility of the use of canonical correlation analysis open to further research.
} 
were removed. The correspondence between these two sets of BSUs is $86.5 \%$. Analogically, from the set of peripheral BSUs based on scalar information those peripheral BSUs, which manifested significant cross-border interaction (bidirectional vector of 100 and more persons), were removed. The correspondence reached $86.7 \%$ in this case.

Finally, the location of peripheral BSUs in the vicinity of the borders of functional meso-regions can be taken into account. In this case, the spatial neighbourhood is assessed in a simple way. Almost $60 \%$ of peripheral BSUs is directly adjacent to meso-regional borders (BSUs of the "first order") and 25\% of them are adjacent to the "first order" BSUs.

The synthesis of partial results is shown in Figure 4, which presents both the spatial distribution of socio-economic peripheries (scalar data) and functional meso-regions together with daily travel-to-work flows between individual municipalities, which are higher than 50 persons (vector data). Importantly, the delineation of functional mesoregions based on daily travel-to-work flows is in accord with the definition of peripheries based on socio-economic data and also in accord with the spatial distribution of daily travelto-work flows. A schematic generalisation of the spatial distribution of core and peripheries, and functional regions is presented in Figure 5. Further comments regarding Figures 4 and 5 are registered in the conclusions.

\section{Conclusions}

In reality, geographical space cannot be and is not homogeneous (as fractals in Fig. 1). Therefore the distribution of all phenomena in a space shows varying degrees of irregularity. For instance, functional regions need not necessarily be only simple, nodal, monocentric structures. They can be polycentric or have other less regular arrangements. The hierarchy of functional regions, as with the distribution of cores and peripheries, does not manifest sharp distinctions but is continuous. In most practical regionalisations which require a certain level of generalisation, however, a unit-step hierarchy has to be used. For instance, in administrative geography several hierarchical levels have to be positively identified. In these cases, the size of regions at one hierarchical level can vary considerably. If the analysed territory does not have distinct physical geographical features and barriers, the regularity of the presented theoretical model increases and starts to resemble the central place theory model (Fig. 5).

Even though it must be admitted that these results and conclusions are based on a specific type of information, not generic, the findings of the paper have certain weight. Moreover, the paper relies on census data, since other suitable information, particularly vector data, is neither easily available (it has to be paid for), nor is it available in sufficient detail, nor does it cover the whole territory of the Czech Republic. The findings of this paper can be viewed in several contexts, from the most discernible to the most debatable: the spatial, hierarchical, and behavioural contexts.

As for the spatial context of the Czech Republic, the peripheries based on scalar information seem to generally fit the spatial pattern of the functional meso-regions based on the vector information (travel-to-work flows). Combining the spatial patterns of both types of data analysed in the paper, the peripheries appear to be the areas where no or little and weak spatial interaction occurs (Fig. 4). In contrast, the

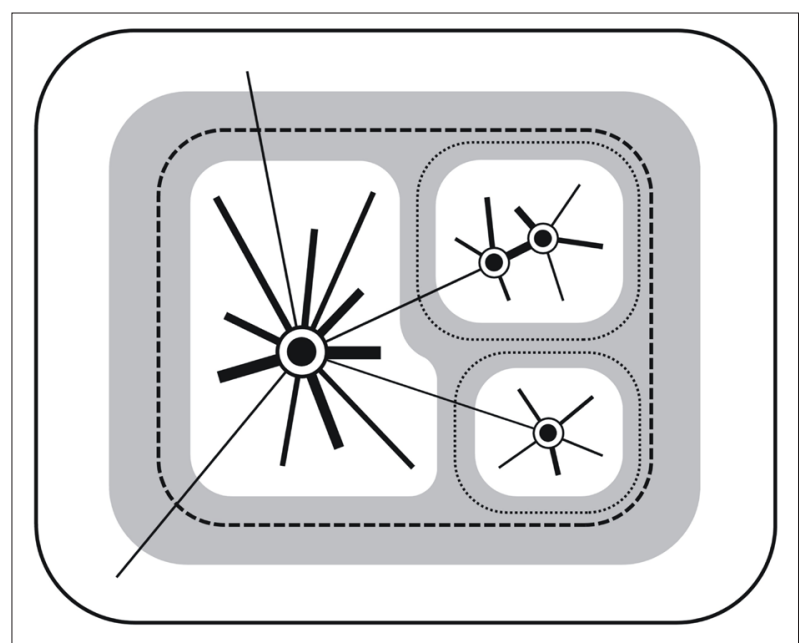

Fig. 5: Spatial interaction pattern, core-periphery dichotomy and boundaries of functional regions Source: author's design

core (central) areas are typified by numerous and intensive interactions. This basic spatial distribution reflects the character of the settlement system. There is a distinction in the spatial pattern of Bohemia (the western two-thirds of the territory of the Czech Republic) based on a monocentric settlement system. The distribution of peripheries conforms rather well to the theoretical model. In contrast, the polycentric settlement system in Moravia and Silesia (the eastern one-third of the territory of the Czech Republic) has a more uneven distribution of peripheries.

As for the hierarchical context, it is at the meso-regional level where the phenomenon is legible most effectively; however, in several cases it is documented even at the micro-regional level (for this see the functional microregions of Trutnov, Jičín, Tábor, Strakonice, Znojmo, Břeclav, etc. in Figs. 3 and 4). In this respect, the paper demonstrates that the explored issue is relevant for at least two hierarchical levels - meso- and micro-regional levels (this conclusion also applies to the macro-regional level, but this case was not researched thoroughly, and there is a significant role of the state boundary and also for orographic effects). The repeatability of spatial patterns at various hierarchical levels supports both the central place theory and fractal theory.

As for the behavioural context, two explanations can be ventured. Either there is a structuring effect of space (i.e. geographical environment in its most general meaning) on both human locational and interaction behaviours, or there is an integrating virtue over these types of human behaviour. It can also be expected that both explanations support each other. In the search for this integrating virtue, and with regard to the data analysed in this paper, either the economy or the social structures can play the integrating role for the locational and interaction behaviour. It is probably both of them and their interplay that forms the integrating virtue. In this sense, the spatial interaction models can be used to explain the linkages between the spatial structure and spatial interaction patterns, and it is also one of the possible directions for future research.

From what has been argued so far, it can be presumed that locational and interaction data are closely interlinked. Even so, several questions remain for future research. For instance, does leisure-related human behaviour 'look' the same? It would be harder to answer this question, because 
of the lack of relevant data rather than because the question would differ theoretically and philosophically from the questions asked in this paper. It can also be assumed that a more concrete spatial manifestation of the leisure-based (or any other relevant) analysis would differ because of different behavioural aspects (particularly the regularity and intensity of the phenomenon), but the basic principles of spatial distributions should be maintained.

\section{Acknowledgements}

This work was funded by the Palacky University Internal Grant Agency through the project No. IGA_PrF_2019_025 "Specifics of behaviourally conditioned temporal-spatial information: methods of its analysis and interpretation". The author would also like to thank anonymous referees and the editor-in-chief for valuable comments regarding the manuscript.

\section{References:}

AGNEW, J.A. (2013): Arguing with regions. Regional Studies, 47(1): 6-17.

ALONSO, W. (1978): A theory of movements. In: Hansen, N. M. [ed.]: Human Settlement Systems: International Perspectives on structure - Change and Public Policy (pp. 197-211). Cambridge, Massachusetts, Ballinger Publishing Company.

AMEDEO, D., GOLLEDGE, R. G., STIMSON, R. J. (2009): Person environment behavior research: investigating activities and experiences in spaces and environments. New York - London, The Guildford Press.

ARLINGHAUS, S. H. (1985): Fractals take a central place. Geografiska Annaler, 67B(2): 83-88.

BARNES, T. J. (2003): The place of locational analysis: a selective and interpretive history. Progress in Human Geography, 27(1): 69-95.

BARNES, T. J. (2004): Placing ideas: genius loci, heterotopia and geography's quantitative revolution. Progress in Human Geography, 28(5): 565-595.

BARNES, T. J. (2009): "Not only... but also": quantitative and critical geography. The Professional Geographer, 61(3): 292-300.

BARNES, T. J. (2010): Taking the pulse of the dead: history and philosophy of geography, 2008-2009. Progress in Human Geography, 34(5): 668-677.

BENNETT, R. J., HAINING, R. P.(1985): Spatial Structure and Spatial Interaction: Modelling Approaches to the Statistical Analysis of Geographical Data. Journal of the Royal Statistical Society, Series A (General), 148(1): 1-36.

BENNETT, R. J., HAINING, R. P., WILSON, A. G. (1985): Spatial structure, spatial interaction, and their integration: a review of alternative models. Environment and Planning A, 17(5): 625-645.

BERNARD, J., ŠIMON, M. (2017): Vnitřní periferie v Česku: Multidimenzionalita sociálního vyloučení ve venkovských oblastech. Sociologický časopis/Czech Sociological Review, 53(1): 3-28.

BERRY, B. J. L. (1961): A method for deriving multi-factor uniform regions. Przegląd geograficzny, 33(2): 263-282.

BERRY, B. J. L. (1968): A synthesis of formal and functional regions using general field theory of spatial behavior.
In: Berry, B. J. L., Marble, D. F. [eds.]: Spatial analysis: a reader in statistical geography (pp. 419-428). Englewood Cliffs, Prentice Hall.

BERRY, B. J. L., GARRISON, W. L. (1958): The Functional Bases of the Central Place Hierarchy. Economic Geography, 34(2): 145-54.

BORGATTI, S. P., EVERETT, M. G. (1999): Models of core/ periphery structures. Social Networks 21: 375-395.

BROWN, L. A., HOLMES, J. (1971): The delimitation of functional regions, nodal regions, and hierarchies by functional distance approaches. Journal of Regional Science, 11(1): 57-72.

BUNGE, W. (1962): Theoretical geography. Lund, Lund Studies in Geography, Series C I, Gleerup.

BYFUGLIEN, J., NORDGÅRD, A. (1973): Region-building a comparison of methods. Norsk Geografisk Tidsskrift Norwegian Journal of Geography, 27(2): 127-151.

CASADO-DÍAZ, J. M. (2000): Local labour market areas in Spain: a case study. Regional Studies, 34(9): 843-856.

CASADO-DÍAZ, J. M., COOMBES, M. (2011): The delineation of $21^{\text {st }}$ century local labour markets areas: a critical review and a research agenda. Boletín de la Asociación de Geógrafos Espańoles, 57: 7-32.

CHEN, Y. (2011): Fractal systems of central places based on intermittency of space-filling. Chaos, Solitons \& Fractals, 44 (8): 619-632.

CHRISTALLER, W. (1933): Die zentralen Orte in Suddeutschland. Jena, Gustav Fischer.

CLIFF, A. D., HAGGETT, P., ORD, J. K., BASSETT, K., DAVIES, R. (1975): Elements of spatial structure. A quantitative approach. Cambridge, Cambridge University Press.

CLIFF, A. D., MARTIN, R. L., ORD, J. K. (1974): Evaluating the friction of distance parameter in gravity models. Regional Studies, 8(3-4): 281-286.

COOMBES, M. G. (2010): Defining labour market areas by analysing commuting data: innovative methods in the 2007 review of travel-to-work areas. In: Stillwell, J., Duke-Williams, O., Dennett, A. [eds.]: Technologies for migration and commuting analysis: spatial interaction data applications (pp. 227-241). Hershey, IGI Global.

COOMBES, M. G., BOND, S. (2008): Travel-to-work areas: the 2007 review. London, Office for National Statistics.

COOMBES, M. G., GREEN, A. E., OPENSHAW, S. (1986): An Efficient Algorithm to Generate Official Statistical Reporting Areas: The Case of the 1984 Travel-to-Work Areas Revision in Britain. The Journal of the Operational Research Society, 37(10): 943-953.

CÖRVERS, F., HENSEN, M., BONGAERTS, D. (2009): Delimitation and coherence of functional and administrative regions. Regional Studies, 43(1): 19-31.

CURRY, L. (1964): The random spatial economy: an exploration in settlement theory. Annals of the association of American geographers, 54(1): 138-146.

CURRY, L. (1972): Spatial analysis of gravity flows. Regional Studies, 6(2): 131-147.

CZECH STATISTICAL OFFICE (2016): Key macroeconomic indicators. Available at: https://www.czso.cz/csu/czso/ hmu_ts. 
DEL CAMPO, C., MONTEIRO, C. M. F., SOARES, J. O. (2008): The European regional policy and the socioeconomic diversity of European regions: A multivariate analysis. European Journal of Operational Research, 187(2): 600-612.

DiSTEFANO, C., ZHU, M., MINDRILA, D. (2009): Understanding and using factor scores: Considerations for the applied researcher. Practical Assessment, Research \& Evaluation, 14(20): 1-11.

DOLNICAR, S., GRÜN, B. (2009). Challenging "factorcluster segmentation". Journal of Travel Research, 47(1): 63-71.

DOLNICAR, S., GRÜN, B. (2011): Three good reasons NOT to use factor-cluster segmentation. Cauthe: $21^{\text {st }}$ National Conference, Adelaide, Australia, 8-11 February 2011.

ERLEBACH, M., TOMÁŠs, M., TONEV, P. (2016): A functional interaction approach to the definition of meso regions: the case of the Czech Republic. Moravian Geographical Reports, 24(2): 37-46.

EVERITT, B. S., LANDAU, S., LEESE, M., STAHL, D. (2011): Cluster analysis. $5^{\text {th }}$ edition. Chichester, John Wiley \& Sons.

FARMER， C. J. Q., FOTHERINGHAM， A. S. (2011): Network-based functional regions. Environment and Planning A, 43(11): 2723-2741.

FERREIRA, L., HITCHCOCK, B. D. (2009): A comparison of hierarchical methods for clustering functional data. Communications in Statistics - Simulation and Computation, 38(9): 1925-1949.

FISCHER, M. M. (1980): Regional taxonomy: a comparison of some hierarchic and non-hierarchic strategies. Regional Science and Urban Economics, 10(4): 503-537.

FISCHER, M. M. (1987): Some fundamental problems in homogeneous and functional regional taxonomy. Bremer Beiträge zur Geographie und Raumplanung, 11: 264-282.

FOTHERINGHAM, A.S. (1981): Spatial structure and distance-decay parameters. Annals of the Association of American Geographers, 71(3): 425-436.

FOTHERINGHAM, A. S. (1986): Modelling hierarchical destination choice. Environment and planning A, 18(3): 401-418.

FOTHERINGHAM，A. S., WEBER, M. J. (1980): Spatial structure and the parameters of spatial interaction models. Geographical Analysis, 12(1): 33-46.

FRANTÁL, B., KLAPKA, P., SIWEK, T. (2012): Lidské chování v prostoru a čase: teoreticko-metodologická východiska [Human Behaviour in Space and Time: Theoretical-Methodological Foundations]. Sociologický časopis / Czech Sociological Review, 48(5): 833-857.

GAN, G., MA, C., WU, J. (2007): Data clustering: theory, algorithms, and applications. ASA-SIAM Series on statistics and applied probability. Philadelphia, SIAM, Alexandria, VA, ASA.

GARRISON, W. L. (1959a): Spatial Structure of the Economy: I. Annals of the Association of American Geographers, 49(2): 232-239.

GARRISON, W. L. (1959b): Spatial Structure of the Economy: II. Annals of the Association of American Geographers, 49(4): 471-482.
GARRISON, W. L. (1960): Spatial Structure of the Economy: III. Annals of the Association of American Geographers, 50(3): 357-373.

GOLLEDGE, R. G., STIMPSON, R. J. (1997): Spatial behavior: a geographical perspective. New York - London, The Guilford Press.

GORDON, A. D. (1987): A review of hierarchical classification. Journal of the Royal Statistical Society A, 150(2): 119-137.

GREER-WOOTEN, B. (1971): Some reflections on systems analysis in geographic research. In: French, H. M., Racine, J. B. [eds.]: Quantitative and Qualitative Geography (pp. 151-174), Ottawa, University of Ottawa Press.

GREGORY, D., JOHNSTON, R., PRATT, G., WATTS, M., WHATMORE, S. [eds.] (2009): The dictionary of human geography. $5^{\text {th }}$ edition. Chichester, John Wiley \& Sons.

GRIFFITH, D.A. (1976). Spatial structure and spatial interaction: A review. Environment and Planning A, 8(7): 731-740.

GRIFFITH, D.A. (2007): Spatial structure and spatial interaction: 25 years later. The Review of Regional Studies, 37(1): 28-38.

GRIFFITH, D. A., JONES, K. G. (1980): Explorations into the relationship between spatial structure and spatial interaction. Environment and Planning A, 12(2): 187-201.

GRIGG, D. (1965): The logic of regional systems. Annals of the Association of American Geographers, 55(3): 465-491.

GRIGG, D. (1967): Regions, models, and classes. In: Chorley, R. J., Haggett, P. [eds.]: Models in Geography (pp. 461509). London, Methuen.

HAGGETT, P. (1965): Locational analysis in human geography. London, Arnold.

HALÁS, M. (2014): Modelovanie priestorového usporiadania a dichotómie centrum - periféria. Geografie, 119(4): 384-405.

HALÁS, M., KLAPKA, P., ERLEBACH, M. (2018): Unveiling spatial uncertainty: a method to evaluate the fuzzy nature of functional regions. Regional Studies. DOI: 10.1080/00343404.2018.1537483.

HALÁS, M., KLAPKA, P., KLADIVO, P. (2014a): Distancedecay functions for daily travel-to-work flows. Journal of Transport Geography, 35: 107-119.

HALÁS, M., KLAPKA, P., TONEV, P. (2014b): A contribution to human geographical regionalisation of the Czech Republic at the mezzo level. In: $17^{\text {th }}$ International Colloquim on Regional Science. Conference Proceedings (pp. 715-721). Brno, Masaryk University.

HALÁS, M., KLAPKA, P., TONEV, P., BEDNÁŘ, M. (2015): An alternative definition and use for the constraint function for rule-based methods of functional regionalisation. Environment and Planning A, 47(5): 1175-1191.

HAN, Q., TIMMERMANS, H. (2006): Towards models of strategic spatial choice behaviour: theory and application issues. GeoJournal, 67(3): 195-206.

HARMAN, H. H. (1976): Modern factor analysis. $3^{\text {rd }}$ edition. Chicago, University of Chicago Press. 
HARVEY, D. W. (1968): Pattern, process, and the scale problem in geographical research. Transactions of the Institute of British Geographers, 45: 71-78.

HELDT CASSEL, S., MACUCHOVA, Z., RUDHOLM, N., RYDELL, A. (2013): Willingness to commute long distance among job seekers in Dalarna, Sweden. Journal of Transport Geography, 28: 49-55.

HOLMES, J.H., HAGGETT, P. (1977): Graph theory interpretation of flow matrices: a note on maximization procedures for identifying significant links. Geographical Analysis, 9(4): 388-399.

ISARD, W. (1956): Location and space-economy: a general theory relating to industrial location, market areas, land use, trade and urban structure. Technology Press of MIT - Wiley, Cambridge, MA - New York.

JOHNSTON, R. J. (1965): Multi-variate regions: a further approach. The Professional Geographer, 17(5): 9-12.

JOHNSTON, R.J. (1970): Grouping and regionalizing: some methodological and technological observations. Economic Geography, 46 (Supplement): 293-305.

JOHNSTON, R. J. (1976): Classification in geography. CATMOG 6. Norwich, GeoAbstracts.

JONES, C. (2017). Spatial economy and the geography of functional economic areas. Environment and Planning B, 44(3): 486-503.

KAISER, H. F. (1960): The application of electronic computers to factor analysis. Educational and Psychological Measurement, 20(1): 141-151.

KARLSSON, C., OLSSON, M. (2006) The identification of functional regions: theory, methods, and applications. The Annals of Regional Science, 40(1): 1-18.

KIBICHO, W. (2010): Community-based Tourism: A FactorCluster Segmentation Approach, Journal of Sustainable Tourism, 16(2): 211-231.

KLAPKA, P., HALÁS, M. (2016): Conceptualising patterns of spatial flows: Five decades of advances in the definition and use of functional regions. Moravian Geographical Reports, 24(2): 2-11.

KLAPKA, P., HALÁS, M., NETRDOVÁ, P., NOSEK, V. (2016): The efficiency of areal units in spatial analysis: Assessing the performance of functional and administrative regions. Moravian Geographical Reports, 24(2): 47-59.

KLAPKA, P., HALÁS, M., TONEV, P. (2013): Functional regions: concept and types. In: $16^{\text {th }}$ International Colloquium on Regional Science. Conference Proceedings. Brno, Masaryk University, 94-101.

KROPP, P., SCHWENGLER, B. (2014): Three-Step Method for Delineating Functional Labour Market Regions. Regional Studies, 50(3): 429-445.

KWAN, M. P., SCHWANEN, T. (2009): Quantitative revolution 2: the critical (re)turn. The Professional Geographer, 61(3): 283-291.

LANKFORD, P. M. (1969): Regionalization: theory and alternative algorithms. Geographical Analysis, 1(2): 196-212.

LATTIN, J., CARROL, J. D., GREEN, P. E. (2003): Analysing Multivariate Data. Duxbury: Thompson Learning.

LEIMGRUBER, W. (1994): Marginality and marginal regions: problems of definition. In: Chang-Yi, D. C. [eds.]: Marginality and Development Issues in Marginal
Regions. Proceedings of Study Group on Development Issues in Marginal Regions (pp. 1-18). Taipei, IGU.

LÖSCH, A. (1940): Die räumliche Ordnung der Wirtschaft. Jena, Gustav Fischer.

MANDELBROT, B. B. (1967): How long is the coast of Britain? Statistical self-similarity and fractional dimension. Science, 156: 636-638.

MARGULES, C. R., FAITH, D. P., BELBIN, L. (1985): An adjacency constraint in agglomerative hierarchical classifications of geographic data. Environment and Planning A, 17(3): 397-412.

MARTÍNEZ-BERNABEU L., FLÓREZ-REVUELTA F., CASADO-DÍAZJ. (2012): Grouping genetic operators for the delineation of functional areas based on spatial interaction. Expert Systems with Applications, 39(8): 6754-6766.

MASSER, I., BROWN, P. J. B. (1975): Hierarchical aggregation procedures for interaction data. Environment and Planning A, 7(5): 509-523.

MATTSSON, L. G., WEIBULL, J. W. (2002): Probabilistic choice and procedurally bounded rationality. Games and Economic Behavior, 41(1): 61-78.

MURRAY, A. T., GRUBESIC, T. H., WEI， R. (2014): Spatially significant cluster detection. Spatial Statistics, 10: 103-116.

MUSIL, J. (1988): Nové pohledy na regeneraci našich měst a osídlení. Územní plánování a urbanismus, 15(2): 67-72.

MUSIL, J., MÜLLER, J. (2008): Vnitřní periferie v České republice jako mechanismus sociální exkluze. Sociologický časopis/Czech Sociological Review, 44(2): 321-348.

NYSTUEN, J. D., DACEY, M. F. (1961): A graph theory interpretation of nodal regions. Regional Science Association, Papers and Proceedings, 7(1): 29-42

PALEVIČIENE, A., DUMČIUVIENE, D. (2015): SocioEconomic Diversity of European Regions: Finding the Impact for Regional Performance. Procedia Economics and Finance, 23: 1096-1101.

PAPPS, K. L., NEWELL, J. O. (2002): Identifying functional labour market areas in New Zealand: a reconnaissance study using travel-to-work data. Discussion Paper 443. Bonn, Institute for the Study of Labor.

PERROUX, F. (1950): Economic space: theory and applications. The Quarterly Journal of Economics, 64(1): 89-104.

RICHARDSON, H. W. (1977): City size and national spatial strategies in developing countries. Washington, D.C., World Bank Staff WP.

ROGERSON, P. A. (2010): Statistical methods for geography: a student's guide. $3^{\text {rd }}$ edition. London, Sage.

ROUSSEEUW, P. J. (1987): Silhouettes: a graphical aid to the interpretation and validation of cluster analysis. Journal of Computational and Applied Mathematics, 20: 53-65.

SACK, R. D. (1972): Geography, geometry, and explanation. Annals of the Association of American Geographers, 62(1): 61-78.

SACK, R. D. (1973): A concept of physical space in geography. Geographical Analysis, 5(1): 16-34.

SACK, R.D. (1974): The spatial separatist theme in geography. Economic Geography, 50(1): 1-19. 
SCHWANEN, T., KWAN, M. P. (2009): "Doing" critical geographies with numbers. The Professional Geographer, 61(4): 459-464.

SHEPPARD, E. S. (1978): Theoretical underpinnings of the gravity hypothesis. Geographical Analysis, 10(4): 386-402.

SMART, M. W. (1974): Labour market areas: uses and definition. Progress in Planning, 2(4): 239-353.

SOJA, E. W. (1980): The socio-spatial dialectic. Annals of the Association of American Geographers, 70(2): 207-225.

SPENCE, N. A., TAYLOR, P. J. (1970): Quantitative Methods in Regional Taxonomy. Progress in Geography, 2: 1-64.

STILLWELL, J. (1991): Spatial interaction models and the propensity to migrate over distance. In: Stillwell, J., Congdon, P. [eds.]: Migration Models: Macro and Micro Approaches (pp. 34-56). London, Belhaven Press.

TAYLOR, P. J. (1983): Distance Decay in Spatial Interactions. CATMOG 2. Norwich, Geo Books.

THOMPSON, B. (2004): Exploratory and confirmatory factor analysis: Understanding concepts and applications. Washington, DC, American Psychological Association.

TIEFELSDORF, M. (2003): Misspecifications in interaction model distance decay relations: A spatial structure effect. Journal of Geographical Systems, 5(1): 25-50.

TOBLER, W. (1970): A computer movie simulating urban growth in the Detroit region. Economic Geography, 46 (Supplement 1): 234-240.

ÜBERLA, K. (1971): Faktorenanalyse. Eine systematische Einführung für Psychologen, Mediziner, Wirtschaftsund Sozialwissenschaftler. Berlin, Heidelberg, New York.
ULLMAN, E. (1980): Geography as spatial interaction. Washington, University of Washington Press.

ULUMAN, M., DOGAN, D. (2012): Comparison of factor score computation methods in factor analysis. Australian Journal of Basic and Applied Sciences, 10(18): 143-151.

VON THÜNEN, J.H. (1826): Der isolierte Staat in Beziehung auf Nationalökonomie und Landwirtschaft. Gustav Fischer, Stuttgart (reprinted 1966).

WALLERSTEIN, I. (1979): The capitalist world economy. Paris, Maison des Sciences de L’Homme.

WARD, J. H. (1963): Hierarchical grouping to optimize an objective function. Journal of the American Statistical Association, 58(301): 236-244.

WATTS, M. (2013): Assessing different spatial grouping algorithms: an application to the design of Australia's new statistical geography. Spatial Economic Analysis, 8(1): 92-112.

WEBER, A. (1909): Über den Standort der Industrien. Erster Teil. Reine Theorie des Standorts. Mit einem mathematischen Anhang von Georg Pick. Tübingen, J. C. B. Mohr (Paul Siebeck).

WYLY, E. (2014): The new quantitative revolution. Dialogues in Human Geography, 4(1): 26-38.

ZIPF, G. K. (1947): The hypothesis of the 'minimum equation' as a unifying social principle: with attempted synthesis. American Sociological Review, 12(6): 627-650.

\section{Please cite this article as:}

ERLEBACH, M., HALÁS, M., DANIEL, J., KLAPKA, P. (2019): Is there congruence in the spatial patterns of regions derived from scalar and vector geographical information? Moravian Geographical Reports, 27(1): 2-14. Doi: 10.2478/mgr-2019-0001. 